Proceedings

\title{
Profiling the Variability of Eucalyptus Essential Oils with Activity against the Phylum Nematoda ${ }^{+}$
}

\author{
Ana Margarida Rodrigues ${ }^{1}$ and Jorge M. S. Faria ${ }^{2,3, *}$
}

Citation: Rodrigues, A.M.; Jorge M.S. Faria Profiling the variability of Eucalyptus essential oils with activity against the phylum Nematoda.

Proceedings 2021, 68, $\mathrm{x}$.

https://doi.org/10.3390/xxxxx

Published: date

Publisher's Note: MDPI stays neutral with regard to jurisdictional claims in published maps and institutional affiliations.

Copyright: (c) 2021 by the authors. Submitted for possible open access publication under the terms and conditions of the Creative Commons Attribution (CC BY) license (http://creativecommons.org/licenses /by/4.0/).
1 Plant Metabolomics Laboratory, Instituto de Tecnologia Química e Biológica António Xavier (ITQB NOVA), Av. da República, 2780-157 Oeiras, Portugal; amargaridacrodrigues@gmail.com

2 MED, Mediterranean Institute for Agriculture, Environment and Development, Institute for Advanced Studies and Research, Évora University, Pólo da Mitra, Ap. 94, 7006-554 Évora, Portugal

3 INIAV, I.P., Instituto Nacional de Investigação Agrária e Veterinária, Quinta do Marquês, 2780-159 Oeiras, Portugal

* Correspondence: fariajms@gmail.com

† Presented at the 1st International Electronic Conference on Biological Diversity, Ecology and Evolution, 1531 March 2021; Available online: https://bdee2021.sciforum.net/.

\begin{abstract}
The genus Eucalyptus (Myrtaceae) comprises more than 800 species, mostly native to Australia. Eucalyptus shoots essential oils (EOs) are well-known for their extremely high qualitative and quantitative variation in terpenes (mainly mono- and sesquiterpenes). These EOs have a wide range of uses, from the taxonomic characterization of populations based on the chemical profiling of EO chemotypes, to industrial applications, including pharmaceutical, agrochemical, and in food and fragrances. In this study, we reviewed the available information concerning the chemical variability of EOs from Eucalyptus spp. assayed against nematodes. Among the most active EOs, those from E. globulus, E. staigeriana, and E. citriodora were more frequently used. EO chemical composition was mainly dominated by 1,8-cineole, limonene, $p$-cymene, citronellal and piperitone in varying proportions. Nematicidal activity of Eucalyptus EOs was reported against animal-parasitic nematodes, including gastrointestinal nematodes (e.g., Haemonchus contortus), plant-parasitic nematodes, such as root-knot nematodes (e.g., Meloidogyne incognita and M. chitwoodi) or the pinewood nematode Bursapelenchus xylophilus, and the free-living nematode Caenorhabditis elegans. Correlation between EO qualitative and quantitative composition with its respective activity may provide valuable information on the nematicidal specificity of EOs. This knowledge can be useful for devising environmentally safer pest management strategies in the conservation of ecosystems biodiversity.
\end{abstract}

Keywords: Bursapelenchus xylophilus; Caenorhabditis elegans; chemical profiling; essential oil; Eucalyptus; Haemonchus contortus; Meloidogyne chitwoodi; Meloidogyne incognita; nematicides; sustainable pest management

\section{Introduction}

Essential oils (EOs) are volatile mixtures, exclusively obtained from plant material by hydro-, steam- or dry- distillation, or in the case of Citrus fruits, mechanically without heating [1]. These volatile mixtures are mainly composed of terpenes (mono-, sesqui-, and di-terpenes) and phenylpropanoids, and are usually dominated by one to three major components at relatively high amounts [2]. The genus Eucalyptus (Myrtaceae family) comprises more than 800 species, mostly native to Australia. Eucalyptus spp. have been extensively explored in the pharmaceutical and cosmetic industries due to their terpene-rich essential oils (EOs), namely high quantities of 1,8-cineole (also referred as Eucalyptol), an oxygenated monoterpenoid used extensively in flavorings, fragrances and cosmetics [3]. In traditional medicine, eucalypt leaves and 1,8-cineole are generally used as cough suppressants. 
Eucalyptus spp. are well-known for the high foliar terpene qualitative and quantitative variations, at the taxa, population, and individual levels, and a large number of chemotypes have been identified [4-9]. Terpenes are a large class of secondary metabolites, with an important ecological role in mediating plant-plant and plant-animal interactions. In the Myrtaceae family, terpenes have been mostly implicated in defensive roles against herbivores and pathogens [7]. EO chemotypes are defined by qualitative and quantitative differences in the EO chemical composition among populations of the same species, due to genetic variations in the regulation of terpene biosynthesis $[4,10,11]$. The occurrence of EO chemotypes has been strongly associated with geographical variation and can reflect the different environmental conditions to which plants are exposed (e.g., altitude, solar exposition, or soil type) [1]. In addition, the frequent occurrence of EO chemotypes within Eucalyptus spp. could implicate differences in biological activities and should be carefully evaluated. Eucalyptus EOs have a wide range of biological activities including anti-microbial, fungicidal, insecticidal/insect repellent, herbicidal, acaricidal and nematicidal [12]. The phylum Nematoda (or Nemathelminthes) comprise roundworms and eelworms (parasites of plants). Nematodes are present in every ecosystem being found in freshwater, marine and terrestrial environments, and can be parasitic (parasites of plants, insects, humans and other animals) or non-parasitic (free-living). They are vermiform, unsegmented, bilaterally symmetrical pseudocelomates, having a pseudocoelom lined with mesoderm, in one side, and with endoderm on the other side. The nematode body is protected by the cuticle, a very complex and evolutionarily plastic structure that functions as protection and is involved in body movement and maintaining shape. Nematodes have digestive, reproductive, nervous and excretory systems, but lack circulatory or respiratory systems [13].

In this study, we reviewed the available information concerning the chemical variability of EOs from Eucalyptus spp. assayed against nematodes (phylum Nematoda). Research was performed with Web of Science ${ }^{\circledR}$ search engine, in all available databases, on published works reporting the composition of EOs used against nematodes, using the topics "Eucalyptus", "nematode" and "essential oil". Information on the Eucalyptus species and EO composition $(\geq 1 \%)$ was collected when available. A total of 17 publications was retrieved reporting on the nematicidal activity of eucalypt EOs [14-30]. These reports were published in journals dedicated to Parasitology (60\%), Veterinary Sciences (47\%) and Agronomy (20\%). Publications dated from 2006 to 2021, with 2011, 2013 and 2015 being the years with the most publications. The listed publications were cited 350 times, with an average of 23.3 citations per work. The citing reports were published in journals specialized in Parasitology (22\%), Veterinary Sciences (16\%), Food Science Technology (11\%) and Plant Sciences (11\%).

\section{Chemical Variability of Eucalyptus Essential Oils}

Chemical composition was reported for a total of 32 EOs tested against plant-parasitic (21), animal-parasitic (10) and free-living nematodes (1). E. citriodora, E. globulus and E. staigeriana were the most studied Eucalyptus species, with seven, three and five EOs tested, respectively. Cluster analysis was performed to determine the similarity between the composition of the tested EOs. Three main clusters were obtained (Figure 1a). EOs from E. citriodora were grouped in one single cluster, revealing a high similarity, and low variability, between EO composition. E. citriodora EO main components were citronellal and isopulegol. EOs from E. globulus were grouped together with EOs from E. saligna, E. camaldulensis, E. botryoides, E. viminalis, E. polyanthemos, E. bosistoana, E. cordieri, E. cinerea, E. smithii and two unidentified Eucalyptus species. EOs from E. globulus revealed an extremely high degree of similarity with E. smithii, E. bosistoana, E. cordieri and E. cinerea. All Eucalyptus spp. included in this cluster were rich in 1,8-cineole and $\alpha$-pinene. The remaining cluster comprised the EOs from E. staigeriana and E. urophylla, E. dives, E. meliodora, E. ficifolia and E. pauciflora. The composition of the EO from these species showed high variability. E. ficiflora and E. pauciflora EOs were rich in $\alpha$-pinene and limonene (only for $E$. 
ficiflora); E. meliodora EO contained mainly $p$-cymene, 1,8-cineole, and cryptone; E. urophylla EO contained mainly $\alpha$-phellandrene and 1,8-cineole; E. dives

EO contained, piperitone, $\alpha$-phellandrene, and $p$-cymene; and E. staigeriana showed a high variability in EO composition, with three EOs rich in limonene and the remaining two EO were rich in geranial, geraniol and methyl geranate.

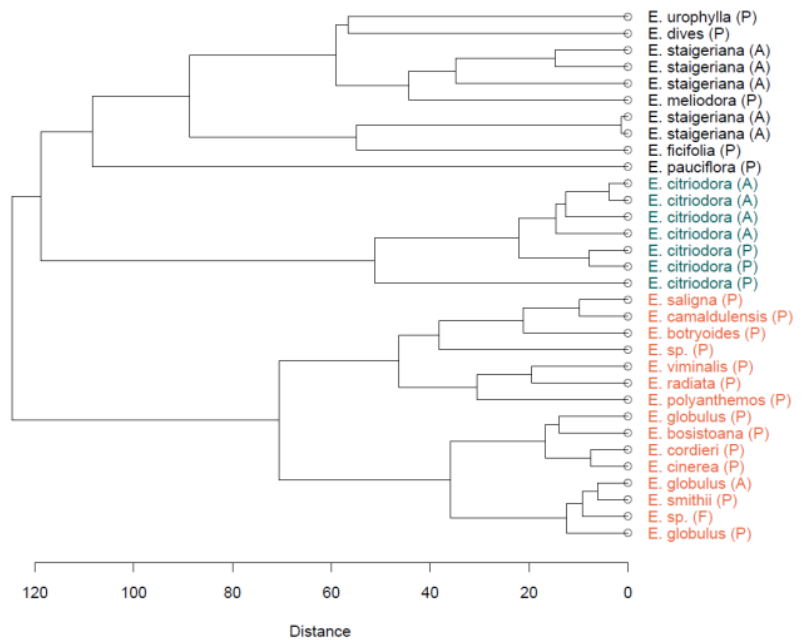

(a)

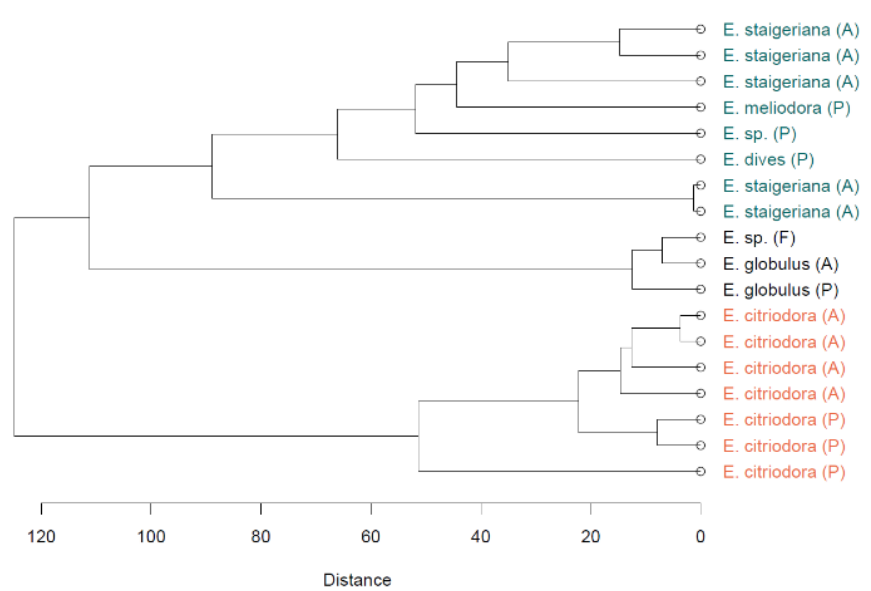

(b)

Figure 1. Dendrogram obtained by cluster analysis of the percentage composition ( $\geq 1 \%)$ of all Eucalyptus essential oils reported (a) and of those with activity against nematodes (b), based on distance and using unweighted pair-group method with arithmetic average (UPGMA) method. A-animal-parasitic nematodes, $\mathrm{P}$-plant-parasitic nematodes and $\mathrm{F}$-freeliving nematodes.

\section{Chemical Composition of Active EOs}

A total of 18 EOs were reported with a high activity against nematodes. Cluster analysis revealed three major clusters, with E. citriodora EOs included in one single cluster, E. globulus and one unidentified Eucalyptus sp. grouped together in another cluster, and E. staigeriana clustered together with E. dives and one unidentified Eucalyptus sp. (Figure 1b). No correlation could be established between EO clustering and activity against specific nematode groups. Despite the small number of reported nematicidal chemically characterized EOs some preliminary considerations could be made regarding activity against the groups of nematodes analyzed. Only one EO was tested against free-living nematodes, thus no substantial comparison can be made with the remaining nematode types. The oxygenated monoterpene 1,8-cineole could be found in EOs active against all nematode types, in amounts $\geq 20 \%$ (Table 1 , Figure 2). The hydrocarbon monoterpene $p$-cymene was found in amounts $\geq 20 \%$ in EOs active against plant-parasitic nematodes while the hydrocarbon monoterpene limonene was only found in amounts $\geq 20 \%$ in EOs active against animal-parasitic nematodes.

Table 1. Minimum and maximum percentages of main components ( $\geq 20 \%)$ of Eucalyptus EOs with activity against plant-parasitic nematodes, animal-parasitic nematodes and free-living nematodes.

\begin{tabular}{cccc}
\hline EO Components (\%) & $\begin{array}{c}\text { Plant Parasitic Nema-Animal Parasitic Nema- } \\
\text { todes }\end{array}$ & todes & Free Living Nematodes \\
\hline$p$-Cymene & $3.1-25.0$ & 2.6 & 3.8 \\
1,8-Cineole & $1.3-91.5$ & $1.7-83.9$ & 82.6 \\
Limonene & - & $7.0-72.9$ & 7.7 \\
Citronellal & $35.8-83.8$ & $5.5-71.8$ & - \\
Piperitone & 40.2 & - & - \\
\hline
\end{tabular}



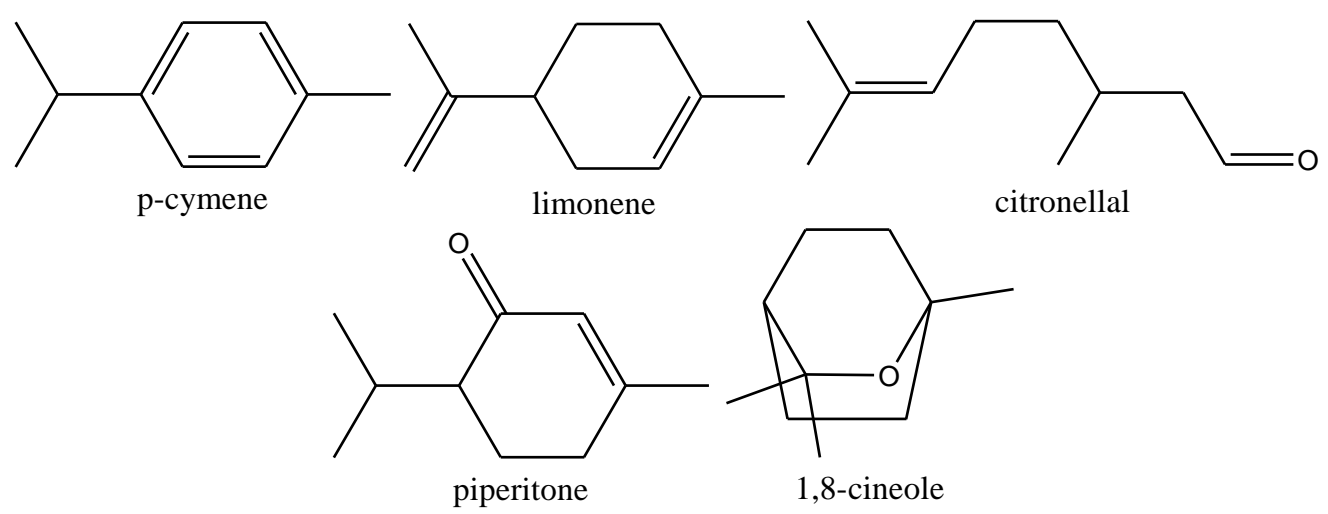

Figure 2. Chemical structures of the main compounds found on nematicidal Eucalyptus essential oils.

The monoterpenic aldehyde citronellal was found in amounts $\geq 20 \%$ in EOs active against plant- and animal-parasitic nematodes while the ketone piperitone was only found in amounts $\geq 20 \%$ in EOs active against plant-parasitic nematodes (Table 1, Figure 2).

\section{Conclusions}

Chemical variability is an important trait of Eucalyptus EOs. In this study, EO composition from Eucalyptus spp. assayed against nematodes was reviewed. Cluster analysis grouped EOs from E. citriodora and E. globulus in two clusters based on the EO main components, namely citronellal and 1,8-cineole, respectively. E. staigeriana EO showed high variability in the EO main components, namely limonene, geranial, geraniol and methyl geranate. Concerning nematicidal EOs, $p$-cymene and 1,8-cineole were ubiquitously present, yet high proportions of limonene and piperitone were exclusive to animal- or plantparasitic nematodes, respectively. Citronellal showed high relative amounts for both animal- and plant-parasitic nematodes. Although supported by very few data, some chemical trends seem to indicate that specificity may occur for nematicidal EOs. A greater number of studies is necessary to understand how Eucalyptus EO chemical variability can influence nematicidal activity. This knowledge can be very valuable for the establishment of precision biocides with neutral environmental impacts.

Author Contributions: Conceptualization, A.M.R. and J.M.S.F.; methodology, A.M.R. and J.M.S.F.; software, A.M.R. and J.M.S.F.; investigation, A.M.R. and J.M.S.F.; resources, A.M.R. and J.M.S.F.; writing-original draft preparation, A.M.R. and J.M.S.F.; writing-review and editing, A.M.R. and J.M.S.F. All authors have read and agreed to the published version of the manuscript.

\section{Institutional Review Board Statement:}

\section{Informed Consent Statement:}

Data Availability Statement:

Conflicts of Interest: The authors declare no conflict of interest.

\section{References}

1. Figueiredo, A.C.; Barroso, J.G.; Pedro, L.G.; Scheffer, J.J.C. Factors affecting secondary metabolite production in plants: Volatile components and essential oils. Flavour Fragr. J. 2008, 23, 213-226, doi:10.1002/ffj.1875.

2. Bakkali, F.; Averbeck, S.; Averbeck, D.; Idaomar, M. Biological effects of essential oils - A review. Food Chem. Toxicol. 2008, 46, 446-475, doi:10.1016/j.fct.2007.09.106.

3. Pino, J.A.; Marbot, R.; Quert, R.; García, H. Study of essential oils of Eucalyptus resinifera Smith, E. tereticornis Smith and Corymbia maculata (Hook.) K. D. Hill \& L. A. S. Johnson, grown in Cuba. Flavour Fragr. J. 2002, 17, 1-4, doi:10.1002/ffj.1026. 
4. Keszei, A.; Brubaker, C.L.; Foley, W.J. A molecular perspective on terpene variation in Australian Myrtaceae. Aust. J. Bot. 2008, 56, 197-213, doi:10.1071/BT07146.

5. Keszei, A.; Brubaker, C.L.; Carter, R.; Köllner, T.; Degenhardt, J.; Foley, W.J. Functional and evolutionary relationships between terpene synthases from Australian Myrtaceae. Phytochemistry 2010, 71, 844-852, doi:10.1016/j.phytochem.2010.03.013.

6. Andrew, R.L.; Keszei, A.; Foley, W.J. Intensive sampling identifies previously unknown chemotypes, population divergence and biosynthetic connections among terpenoids in Eucalyptus tricarpa. Phytochemistry 2013, 94, 148-158, doi:10.1016/j.phytochem.2013.05.002.

7. Padovan, A.; Keszei, A.; Külheim, C.; Foley, W.J. The evolution of foliar terpene diversity in Myrtaceae. Phytochem. Rev. 2014, 13, 695-716, doi:10.1007/s11101-013-9331-3.

8. Bustos-Segura, C.; Dillon, S.; Keszei, A.; Foley, W.J.; Külheim, C. Intraspecific diversity of terpenes of Eucalyptus camaldulensis (Myrtaceae) at a continental scale. Aust. J. Bot. 2017, 65, 257, doi:10.1071/BT16183.

9. Faria, J.M.S.; Lima, A.S.; Mendes, M.D.; Leiria, R.; Geraldes, D.A.; Figueiredo, A.C.; Trindade, H.; Pedro, L.G.; Barroso, J.G.; Sanches, J. Eucalyptus from Mata Experimental do Escaroupim (Portugal): Evaluation of the essential oil composition from sixteen species. Acta Hortic. 2011, 925, 61-66, doi:10.17660/ActaHortic.2011.925.7.

10. Figueiredo, A.C. Biological properties of essential oils and volatiles: Sources of variability. Nat. Volatiles Essent. Oils 2017, 4, 113.

11. Rodrigues, A.M.; Mendes, M.D.; Lima, A.S.; Barbosa, P.M.; Ascensão, L.; Barroso, J.G.; Pedro, L.G.; Mota, M.M.; Figueiredo, A.C. Pinus halepensis, Pinus pinaster, Pinus pinea and Pinus sylvestris essential oils chemotypes and monoterpene hydrocarbon enantiomers, before and after inoculation with the pinewood nematode Bursaphelenchus xylophilus. Chem. Biodivers. 2017, 14, e1600153, doi:10.1002/cbdv.201600153.

12. Batish, D.R.; Singh, H.P.; Kohli, R.K.; Kaur, S. Eucalyptus essential oil as a natural pesticide. For. Ecol. Manag. 2008, 256, 21662174, doi:10.1016/j.foreco.2008.08.008.

13. Basyoni, M.M.A.; Rizk, E.M.A. Nematodes ultrastructure: Complex systems and processes. J. Parasit. Dis. 2016, 40, 1130-1140, doi:10.1007/s12639-015-0707-8.

14. Ibrahim, S.K.; Traboulsi, A.F.; El-Haj, S. Effect of essential oils and plant extracts on hatching, migration and mortality of Meloidogyne incognita. Phytopathol. Mediterr. 2006, 45, 238-246, doi:10.14601/Phytopathol_Mediterr-1828.

15. Macedo, I.T.F.; Bevilaqua, C.M.L.; Oliveira, L.M.B. de; CamurÇa-Vasconcelos, A.L.F.; Vieira, L. da S.; Oliveira, F.R.; QueirozJunior, E.M.; Portela, B.G.; Barros, R.S.; Chagas, A.C.S. Atividade ovicida e larvicida in vitro do óleo essencial de Eucalyptus globulus sobre Haemonchus contortus. Rev. Bras. Parasitol. Vet. 2009, 18, 62-66, doi:10.4322/rbpv.01803011.

16. Macedo, I.T.F.; Bevilaqua, C.M.L.; de Oliveira, L.M.B.; Camurça-Vasconcelos, A.L.F.; Vieira, L. da S.; Oliveira, F.R.; QueirozJunior, E.M.; Tomé, A. da R.; Nascimento, N.R.F. Anthelmintic effect of Eucalyptus staigeriana essential oil against goat gastrointestinal nematodes. Vet. Parasitol. 2010, 173, 93-98, doi:10.1016/j.vetpar.2010.06.004.

17. Macedo, I.T.F.; Bevilaqua, C.M.L.; Oliveira, L.M.B. de; Camurça-Vasconcelos, A.L.F.; Vieira, L. da S.; Amóra, S. dos S.A. Evaluation of Eucalyptus citriodora essential oil on goat gastrointestinal nematodes. Rev. Bras. Parasitol. Vet. 2011, 20, 223-227, doi:10.1590/S1984-29612011000300009.

18. Ntalli, N.G.; Ferrari, F.; Giannakou, I.; Menkissoglu-Spiroudi, U. Phytochemistry and nematicidal activity of the essential oils from 8 greek lamiaceae aromatic plants and 13 terpene components. J. Agric. Food Chem. 2010, 58, 7856-7863, doi:10.1021/jf100797m.

19. De Aquino Mesquita, M.; e Silva Júnior, J.B.; Panassol, A.M.; de Oliveira, E.F.; Vasconcelos, A.L.C.F.; de Paula, H.C.B.; Bevilaqua, C.M.L. Anthelmintic activity of Eucalyptus staigeriana encapsulated oil on sheep gastrointestinal nematodes. Parasitol. Res. 2013, 112, 3161-3165, doi:10.1007/s00436-013-3492-2.

20. Ribeiro, W.L.C.; Macedo, I.T.F.; dos Santos, J.M.L.; de Oliveira, E.F.; Camurça-Vasconcelos, A.L.F.; de Paula, H.C.B.; Bevilaqua, C.M.L. Activity of chitosan-encapsulated Eucalyptus staigeriana essential oil on Haemonchus contortus. Exp. Parasitol. 2013, 135, 24-29, doi:10.1016/j.exppara.2013.05.014.

21. Ribeiro, J.C.; Ribeiro, W.L.C.; Camurça-Vasconcelos, A.L.F.; Macedo, I.T.F.; Santos, J.M.L.; Paula, H.C.B.; Araújo Filho, J.V.; Magalhães, R.D.; Bevilaqua, C.M.L. Efficacy of free and nanoencapsulated Eucalyptus citriodora essential oils on sheep gastrointestinal nematodes and toxicity for mice. Vet. Parasitol. 2014, 204, 243-248, doi:10.1016/j.vetpar.2014.05.026.

22. Laquale, S.; Candido, V.; Avato, P.; Argentieri, M.P.; D'Addabbo, T. Essential oils as soil biofumigants for the control of the root-knot nematode Meloidogyne incognita on tomato. Ann. Appl. Biol. 2015, 167, 217-224, doi:10.1111/aab.12221.

23. Ribeiro, W.L.C.; Camurça-Vasconcelos, A.L.F.; Macedo, I.T.F.; dos Santos, J.M.L.; de Araújo-Filho, J.V.; de Carvalho Ribeiro, J.; de Abreu Pereira, V.; de Araújo Viana, D.; de Paula, H.C.B.; Bevilaqua, C.M.L. In vitro effects of Eucalyptus staigeriana nanoemulsion on Haemonchus contortus and toxicity in rodents. Vet. Parasitol. 2015, 212, 444-447, doi:10.1016/j.vetpar.2015.07.019. 
24. Ribeiro, W.L.C.; Camurça-Vasconcelos, A.L.F.; dos Santos, J.M.L.; Macedo, I.T.F.; de Carvalho Ribeiro, J.; de Oliveira, E.F.; de Paula, H.C.B.; Bevilaqua, C.M.L. The use of Eucalyptus staigeriana nanoemulsion for control of sheep haemonchosis. Pesqui. Vet. Bras. 2017, 37, 221-226, doi:10.1590/s0100-736x2017000300004.

25. De Araújo-Filho, J.V.; Ribeiro, W.L.C.; André, W.P.P.; Cavalcante, G.S.; de C.M. Guerra, M.; Muniz, C.R.; Macedo, I.T.F.; Rondon, F.C.M.; Bevilaqua, C.M.L.; de Oliveira, L.M.B. Effects of Eucalyptus citriodora essential oil and its major component, citronellal, on Haemonchus contortus isolates susceptible and resistant to synthetic anthelmintics. Ind. Crops Prod. 2018, 124, 294299, doi:10.1016/j.indcrop.2018.07.059.

26. De Araújo-Filho, J.V.; Ribeiro, W.L.C.; André, W.P.P.; Cavalcante, G.S.; Rios, T.T.; Schwinden, G.M.; da Rocha, L.O.; Macedo, I.T.F.; de Morais, S.M.; Bevilaqua, C.M.L.; et al. Anthelmintic activity of Eucalyptus citriodora essential oil and its major component, citronellal, on sheep gastrointestinal nematodes. Rev. Bras. Parasitol. Vet. 2019, 28, 644-651, doi:10.1590/s198429612019090.

27. Kundu, A.; Dutta, A.; Mandal, A.; Negi, L.; Malik, M.; Puramchatwad, R.; Antil, J.; Singh, A.; Rao, U.; Saha, S.; et al. A Comprehensive in vitro and in silico Analysis of Nematicidal Action of Essential Oils. Front. Plant Sci. 2021, 11, 1-15, doi:10.3389/fpls.2020.614143.

28. Lanzerstorfer, P.; Sandner, G.; Pitsch, J.; Mascher, B.; Aumiller, T.; Weghuber, J. Acute, reproductive, and developmental toxicity of essential oils assessed with alternative in vitro and in vivo systems. Arch. Toxicol. 2021, 95, 673-691, doi:10.1007/s00204-02002945-6.

29. Faria, J.M.S.; Barbosa, P.; Bennett, R.N.; Mota, M.; Figueiredo, A.C. Bioactivity against Bursaphelenchus xylophilus: Nematotoxics from essential oils, essential oils fractions and decoction waters. Phytochemistry 2013, 94, 220-228, doi:10.1016/j.phytochem.2013.06.005.

30. Faria, J.M.S.; Sena, I.; Ribeiro, B.; Rodrigues, A.M.; Maleita, C.M.N.; Abrantes, I.; Bennett, R.; Mota, M.; da Silva Figueiredo, A.C. First report on Meloidogyne chitwoodi hatching inhibition activity of essential oils and essential oils fractions. J. Pest Sci. 2016, 89, 207-217, doi:10.1007/s10340-015-0664-0. 